\title{
Where's the Catch? Shifting Stocks, International Fisheries Management and the Climate Change Conundrum
}

\author{
Richard Caddell
}

'[I]t is a well-established principle of the law of nations that the state of things that actually exists and has existed for a long time should be changed as little as possible'. ${ }^{1}$

'[F]isheries face a serious new challenge as climate change drives the ocean to conditions not experienced historically'. ${ }^{2}$

\section{Introduction}

The divergent subjects of multilateral regulation represented within this volume stand as a formidable testament to the breadth of the contribution made by Robin Churchill to the study of international law over the course of the past five decades. It may nevertheless be suggested that his extensive and enduring legacy of scholarship is most prominently and thematically associated with the law of the sea and international environmental law. Within this context, and positioned at one of the many points of the porous frontier at which these two broad areas of international law intersect and commingle, Churchill's work has been of particular value in advancing the literature on the law of international fisheries, which continues to occupy a central concern in the regulation of marine resources. This chapter accordingly examines the contemporary management of global fish stocks as a fitting achievement of international law, albeit one that reflects many of the inherent strengths and frailties of multilateral governance canvassed elsewhere in this book.

Viewed panoramically, Churchill's work on these issues has encapsulated three broad themes. In the first instance, he has engaged strongly with the perennial difficulties encountered in securing compliance with important unifying obligations. A clear sense of fair play has long permeated Churchill's writings and, while pragmatic as to the drivers and incentives that tempt individual operators to disregard the law, he has maintained a firm belief that cherry-picking compliance with international commitments should not be tacitly accepted as the cost of doing multilateral business. ${ }^{3}$ Moreover, and allied to this, Churchill has also concentrated on the role that dispute resolution can - and should - play in these endeavours, both as a means of promoting compliance and in advancing a workable and consistent interpretation of key instruments. ${ }^{4}$ Secondly, the coherence of international governance structures has also been a core consideration, notably in promoting institutional efficiency and in securing the legitimacy

\footnotetext{
${ }^{1}$ The Grisbådarna Case (Norway v. Sweden), Award of 23 October 1909 [1909] 11 RIA 155, 161.

${ }^{2}$ M Pinsky et al., 'Preparing Ocean Governance for Species on the Move' (2018) 360 Science 1189, 1189.

${ }^{3}$ See for instance R Churchill, 'The Persisting Problem of Non-Compliance with the Law of the Sea Convention: Disorder in the Oceans' (2012) 27 International Journal of Marine and Coastal Law 813, 815.

${ }^{4} \mathrm{R}$ Churchill, 'The Jurisprudence of the International Tribunal for the Law of the Sea Relating to Fisheries: Is There Much in the Net?' (2007) 22 International Journal of Marine and Coastal Law 383, 423-424.
} 
of multilateral machinery. ${ }^{5}$ Thirdly, Churchill's work has retained a foundation of concern for the health of the (marine) environment and the role that law can play in facilitating its longterm protection, while also remaining acutely mindful of its structural and normative limitations. ${ }^{6}$

Arguably the most pressing current issue that prospectively unites these common themes is the threat posed to marine ecosystems by climate change. One of the cornerstone accomplishments of modern international law has been the further codification of the law of the sea, primarily through the adoption of the United Nations Convention on the Law of the Sea $1982 .{ }^{7}$ This framework has had a profound impact upon the governance of ocean space and has brought a considerable degree of normative clarity to the politically-charged question of entitlements to marine living resources. Nevertheless, the maturation of international fisheries law has provided no panacea to the problems facing global fish stocks, ${ }^{8}$ which remain in a troubling state and with concerns consistently raised by overfishing, excessive capacity, environmental damage and serial non-compliance. These regulatory shortcomings are compounded by the present and future impacts of climate change and associated processes upon fisheries resources, ${ }^{9}$ which will exacerbate current management deficiencies and exert unprecedented pressures upon long-standing legal structures. One particularly pressing new challenge in this respect pertains to the changing distributional patterns of many fish and inter-dependent species, influenced by rising sea temperatures and ocean acidification, with current projections indicating their eventual displacement to deeper waters and the Polar Regions. This will inevitably have profound implications for future fisheries management, as some states experience an influx of new stocks while others endure a net loss of resources. While international law has brokered a series of solutions to past problems of access and allocation, the challenges posed by climate change threaten to undermine these hard-won achievements. The future success of international fisheries management will therefore hinge upon the development of far-sighted legal and management solutions to mitigate these impacts, in a context of scientific and political uncertainty and demands for increased flexibility in the regulation of marine living resources.

This contribution therefore considers how international law has responded to climate-induced shifts in fish stocks, an issue that will become increasingly exigent over the course of the coming decades. To this end, this chapter first outlines current and prospective trends in the distribution of commercially significant fish stocks and the limitations of current legal instruments in confronting these shifts. This chapter then examines some of the more promising achievements of international law in promoting the anticipatory management of shifting fisheries. Subsequently, this chapter evaluates the current unsatisfactory treatment of climate

\footnotetext{
5 RR Churchill and G Ulfstein, 'Autonomous Institutional Arrangements in Multilateral Environmental Agreements: A Little-Noticed Phenomenon in International Law' (2000) 94 American Journal of International Law 623.

${ }^{6}$ R Churchill, 'The LOSC Regime for Protection of the Marine Environment - Fit for the Twenty-first Century?' in R Rayfuse, Research Handbook on International Marine Environmental Law (Cheltenham, Edward Elgar, 2015) 3-30.

71833 UNTS 3 ('LOSC').

${ }^{8}$ As noted by the UN Food and Agriculture Organization (FAO) in its biennial review of global fisheries trends, ' $[\mathrm{t}]$ he state of marine fishery resources, based on FAO's monitoring of assessed marine fish stocks, has continued to decline': The State of World Fisheries and Aquaculture 2018 - Meeting the Sustainable Development Goals (Rome, FAO, 2018) 6.

${ }^{9}$ For a sobering overview see WWL Cheung, VWY Lam, Y Ota and W Swartz. 'Modelling Future Oceans: The Present and Emerging Future of Fish Stocks and Fisheries' in R Caddell and EJ Molenaar (eds), Strengthening International Fisheries Law in an Era of Changing Oceans (Oxford, Hart, 2019) 13, 15-17.
} 
change concerns by regional fisheries management organisations (RFMOs), before identifying further areas in need of concerted attention for the international framework in addressing the regulatory challenges posed by the impacts of climate change upon global fish stocks.

\section{Shifting Fish Stocks and the Limits of Current Legal Frameworks}

The elaboration of a framework for the governance of international fisheries resources under the LOSC and associated instruments may be rightly considered a distinct achievement of international law, albeit one that is qualified by ambiguity and persisting lacunae. Fisheries are addressed within two separate Parts of the LOSC, engaging rights and duties of states within their Exclusive Economic Zones (EEZ) and on the high seas respectively. With regard to the EEZ, coastal states exercise sovereign rights for the purpose of exploring and exploiting, conserving and managing natural resources, including fisheries. ${ }^{10}$ Nevertheless, these rights are tempered by a series of obligations aimed at conserving stocks of marine living resources and promoting their optimal utilisation. Under Article 61(1) a coastal state is charged with determining the total allowable catch (TAC) of fish in its EEZ, and is required, 'taking into account the best scientific evidence available to it' to institute proper conservation and management measures to ensure that stocks are not endangered by over-exploitation. ${ }^{11}$ Such measures are intended to maintain or restore populations at levels that are capable of supporting exploitation at maximum sustainable yield (MSY), specifically taking into account 'relevant environmental and economic factors' as well as fishing patterns, the interdependence of stocks and 'generally recommended international minimum standards', ${ }^{12}$ while also considering the effects of harvesting on those species that are associated with or dependent upon the target stock. ${ }^{13}$

Article 62 obliges coastal states to promote the objective of optimal utilisation without prejudice to these preceding criteria. ${ }^{14}$ To this end, coastal states are to determine their capacity to harvest the fish stocks located within these waters and grant access to other states to any surplus, ${ }^{15}$ an often lucrative application of EEZ entitlements. Allocative decisions in this respect are considered to be an exercise of the sovereignty of the coastal states over the natural resources of its EEZ and are accordingly in principle non-justiciable, lying outside the broad framework of compulsory dispute resolution elaborated under the LOSC, ${ }^{16}$ subject to rather limited requirements to consider the interests of landlocked and geographically disadvantaged states in the process ${ }^{17}$ and the need to minimise economic dislocation for those constituents that had played a key role in the development of the fishery in question. ${ }^{18}$ In accessing the surplus, foreign fishers must comply with pertinent conditions and regulations that may be

\footnotetext{
${ }^{10}$ Article 56(1)(a).

${ }^{11}$ Article 61(2).

12 Article 61(3).

13 Article 61(4).

${ }^{14}$ Article 62(1).

15 Article 62(2).

16 Article 297(3)(a). The position of transboundary stocks is rather more nuanced, however, with disputes concerning the high seas appearing to fall outside this exception: see Churchill (n.4) 389-90 and AE Boyle, 'Problems of Compulsory Jurisdiction and the Settlement of Disputes relating to Straddling Fish Stocks' (1999) 14 International Journal of Marine and Coastal Law 1.

${ }^{17}$ Articles 69 and 70.

${ }^{18}$ Article 62(3); see further below.
} 
elaborated ${ }^{19}$ and enforced ${ }^{20}$ by the coastal state. With a modest volume of catches occurring solely on the high seas, ${ }^{21}$ these provisions are thus of enduring significance in framing international rights and responsibilities over the exploitation of fish.

Beyond the confines of national jurisdiction, fishing has long been recognised as one of the fundamental freedoms of the high seas, a position currently enshrined in Article 87(1), albeit tempered by the requirement to exercise 'due regard' for the interests of other states and rights pertaining to the International Seabed Area. ${ }^{22}$ This is further constrained in principle by the need to adhere to pertinent obligations applied within ${ }^{23}$ and beyond the letter of the LOSC. As far as the 1982 Convention is concerned, states have a duty to take - either individually or in cooperation with others - such measures as may be necessary for the conservation of the living resources of the high seas. ${ }^{24}$ While nebulously drawn, these requirements substantively mirror the core elements of the EEZ regime and aim to secure a consistent harvest of fish at MSY, taking into consideration the ecological coexistence of fish stocks and their wider ecosystems. ${ }^{25}$ Although fishing on the high seas is technically open to all states, irrespective of capacity or coastal presence, such fisheries have been the preserve of a relatively small number of states in practice. ${ }^{26}$

Fish nevertheless have little respect for presumptive human-drawn boundaries. Few commercially significant stocks are 'discrete', in that they are confined purely to the high seas ${ }^{27}$ or are located exclusively within the jurisdictional waters of a lone coastal state. Fish are predominantly either transboundary in nature, in that they regularly move between the EEZs of two or more coastal states, or are straddling stocks that transit between at least one EEZ and the high seas, while others pursue extensive migratory routes that see them traverse a series of maritime boundaries, both within and beyond the confines of national jurisdiction. Collectively, these species are addressed under the rather insipid wording of Article 63, which requires States to 'seek, either directly or through appropriate sub-regional or regional organisations to agree on the measures necessary' for the conservation of such stocks. Similarly perfunctory obligations are established under Article 64 in respect of highly migratory species, for which states are to 'cooperate ... with a view to' ensuring the conservation and management of sixteen named families of species, primarily tunas, defined as such in Annex I to the Convention. In principle, the small number of species currently designated 'highly migratory' could be extended, although in practice the protracted amendment processes of the LOSC appear unlikely to be successfully pursued ${ }^{28}$ and the list is thus expected to remain closed to

\footnotetext{
${ }^{19}$ Article 62(4) prescribes a non-exhaustive list of elements that may be prospectively regulated by the coastal state in respect of foreign fleets within the EEZ.

${ }^{20}$ Article 73.

${ }^{21}$ UR Sumaila et al., 'Winners and Losers in a World where the High Seas is Closed to Fishing' (2015) 5 Scientific Reports 8481.

22 Article 87(2).

${ }^{23}$ Specifically Articles 63(2) and 64-67, addressing highly migratory species, marine mammals and anadromous and catadromous stocks respectively: Article 116(b).

24 Articles 117-119.

${ }^{25}$ Article 119(1).

${ }^{26}$ Sumaila (n.21). This is mainly attributed to a lack of nutritional imperative to fish on the high seas, as well as logistical and commercial constraints.

${ }^{27}$ Sumaila, ibid. (noting that less than $2 \%$ of currently fished species are discrete high seas stocks).

${ }^{28}$ Article 312. On the difficulties of amending the Convention see A Boyle, 'Further Development of the Law of the Sea Convention: Mechanisms for Change' (2005) 54 International and Comparative Law Quarterly 563. Alternatively, the constituent treaties of some RFMOs have elaborated more nuanced definitions of the highly migratory species covered by their mandates in order to address a fuller range of species: D Owen, 'Annex I' in A Proelss (ed), United Nations Convention on the Law of the Sea (Munich, Beck/Hart/Nomos, 2017) 2049, 2064.
} 
other species, irrespective of biological behaviour. The tone of Article 64 appears oriented towards the regulation of specific fish, although its interpretation has been muddied by its lingering application to a small number of marine mammals due to complexities in its drafting process. ${ }^{29}$ Ultimately, these ambiguities illustrate an overarching trend, noted with gentle understatement by Churchill, that "many of the fisheries provisions of the LOSC are broadly drawn and lacking in precision'. ${ }^{30}$

The deficiencies of Articles 63 and 64 have been addressed to a considerable extent by the adoption of a specific Implementation Agreement to further elaborate guiding principles and commitments regarding these important fish species. ${ }^{31}$ The UNFSA, which provides normative supplementation to the fisheries regime of the LOSC yet remains a self-standing treaty, ${ }^{32}$ has been of significant operative value in advancing international fisheries management. The UNFSA does not prescribe specific management measures for fisheries. Instead, its value lies in its articulation of overarching governance expectations for current and future RFMOs, notably through enhanced transparency, participatory and administrative practices. ${ }^{33}$ It has also been instrumental in promoting the ecosystem-based ${ }^{34}$ and precautionary ${ }^{35}$ approaches to fisheries that had been broadly absent from preceding instruments, elaborating expectations for securing compatibility between conservation measures adopted in respect of the high seas and areas under national jurisdiction, ${ }^{36}$ as well as elucidating enforcement duties ${ }^{37}$ and dispute resolution $^{38}$ requirements. Most significantly the UNFSA has provided a regulatory template for the constituent treaties of new RFMOs to follow, ${ }^{39}$ while also inspiring older structures to 'retro-fit' clearer environmental obligations into their respective mandates, ${ }^{40}$ thereby entrenching these requirements as core expectations of rational governance for transboundary stocks. Indeed, as Harrison observes, the principles established under the UNFSA 'not only provide a check-list for evaluating the functioning of fisheries cooperation, but they also provide an important baseline for states when negotiating the establishment of new cooperative mechanisms, whether they apply to straddling and highly migratory stocks or discrete high seas stocks'. ${ }^{41}$

\footnotetext{
${ }^{29}$ CSG Jefferies, Marine Mammal Conservation and the Law of the Sea (Oxford, Oxford University Press, 2016) 176-183. Article 65 exempts marine mammals from the expectations of optimal utilisation inherent in the EEZ regime, a provision drafted concurrently with Article 64. Contemporary accounts suggest that marine mammals were intended to be addressed separately, yet a small number of cetaceans remain listed on Annex I to the interpretive detriment of these provisions.

${ }^{30}$ Churchill (n.4) 387.

31 Agreement for the Implementation of the Provisions of the United Nations Convention on the Law of the Sea of 10 December 1982 relating to the Conservation and Management of Straddling Fish Stocks and Highly Migratory Fish Stocks; 2167 UNTS 3 ('UNFSA').

${ }^{32}$ UNFSA, Article 4.

${ }^{33}$ See especially Articles 8-14.

${ }^{34}$ Article 5.

${ }^{35}$ Article 6.

${ }^{36}$ Article 7.

37 Articles 18-23.

${ }^{38}$ Articles 30-32.

${ }^{39}$ See R Caddell, 'International Fisheries Law and Interactions with Global Regimes and Processes' in Caddell and Molenaar (n.9) 133, 147-148.

$40 \mathrm{Z}$ Scanlon, "The Art of "Not Undermining": Possibilities within Existing Architecture to Improve Environmental Protections in Areas beyond National Jurisdiction' (2018) 75 ICES Journal of Marine Science 405, 410.

${ }^{41}$ J Harrison, 'Key Challenges Relating to the Governance of Regional Fisheries' in Caddell and Molenaar (n.9) 79, 80-81.
} 
Notwithstanding these developments, the fisheries provisions of the LOSC - and indeed those of the UNFSA - operate largely on the assumption that fishing grounds will remain fundamentally static and predictable and that fish stocks will continue to provide a perpetual bounty of resources at MSY. However, it is has become increasingly evident that the impacts of climate change and associated processes are challenging these assumptions. Rising sea temperatures and ocean acidification are influencing the current and projected distribution patterns of fish species, with many stocks now 'undergoing phenological and geographical shifts as a result of warming'. ${ }^{42}$ These shifts are gradual but nor are they negligible, with fish and other inter-dependent marine species moving into new areas at a rate of up to 70 $\mathrm{km} /$ decade. ${ }^{43}$ Current predictions indicate a general trend towards the eventual displacement of numerous fish species to deeper ocean waters and the Polar Regions, ${ }^{44}$ with a corresponding reduction in catch potential in the Tropics. ${ }^{45}$ Indeed, warm-water species have been represented in elevated numbers in global catches in recent years ${ }^{46}$ a trend that has been primarily attributed to the increased geographical range of these fish caused by rising ocean temperatures. ${ }^{47}$ Distributional shifts are becoming apparent on a regional basis for particular species, ${ }^{48}$ but their impacts have been most keenly felt on a more national level, with temperature spikes and localised heatwaves having prompted the displacement of substantial volumes of biomass in a number of key fishing locations, ${ }^{49}$ which has considerable socio-economic implications for particular constituencies in both developed ${ }^{50}$ and developing ${ }^{51}$ countries.

Significant adjustments to the compositions of national EEZs are likely to result from climateinduced shifts in the mid- and long-term future. Much depends upon the ultimate rate of warming, ${ }^{52}$ but permanent changes to the distribution of marine species are expected even if there is full and universal compliance with the more ambitious elements of current climate change targets. ${ }^{53}$ The displacement, to at least some degree, of stocks previously present in the national EEZ of one state into that of another is projected to occur in up to $35 \%$ of all present EEZs by $2100 .{ }^{54}$ These readjustments will have profound economic, social and international relations consequences. Inevitably, shifting stocks will present inviting commercial possibilities for coastal states gaining an influx of new resources, particularly in more

\footnotetext{
42 J-P Gattuso et al., 'Contrasting Futures for Ocean and Society from Different Anthropogenic CO2 Emissions Scenarios' (2015) 349 Science 39, 39.

${ }^{43}$ ES Poloczanska et al., 'Global Imprint of Climate Change on Marine Life' (2013) 3 Nature Climate Change 923.

${ }^{44}$ AL Perry et al., 'Climate Change and Distribution Shifts in Marine Fishes' (2005) 308 Science 1912, $1912-$ 1915.

${ }^{45}$ ML Pinsky et al., 'Marine Taxa Track Local Climate Velocities' (2013) 341 Science 1239.

${ }^{46}$ UR Sumaila et al., 'Climate Change Impacts on the Biophysics and Economics of World Fisheries' (2011) 1 Nature Climate Change 449, 451.

${ }^{47}$ WWL Cheung, R Watson and D Pauly, 'Signature of Ocean Warming in Global Fisheries Catch' (2013) 497 Nature 365, 365-66.

${ }^{48}$ I Montero-Serra, M Edwards and MJ Genner, 'Warming Shelf Seas Drive the Subtropicalization of European Pelagic Fish Communities' (2015) 21 Global Change Biology 144, 149-150.

${ }^{49}$ WWL Cheung and TL Frölicher, 'Marine Heatwaves Exacerbate Climate Change Impacts for Fisheries in the Northeast Pacific' (2020) 10 Scientific Reports 6678.

${ }^{50}$ ML Pinsky and M Fogarty, 'Lagged Social-ecological Responses to Climate and Range Shifts in Fisheries' (2012) 115 Climatic Change 883.

${ }^{51}$ R Blasiak et al., 'Climate Change and Marine Fisheries: Least-developed Countries Top Global Index of Vulnerability (2017) 6 PLoS One e0179632.

${ }^{52}$ VWY Lam et al., 'Projected Change in Global Fisheries Revenues under Climate Change' (2016) 6 Scientific Reports 32607.

${ }^{53}$ WWL Cheung, G Reygondeau and TL Frölicher, 'Large Benefits to Marine Fisheries of Meeting the $1.5^{\circ} \mathrm{C}$ Global Warming Target' (2016) 354 Science 1591.

${ }^{54}$ Pinsky (n.2), 1190.
} 
temperate and northerly waters. ${ }^{55}$ This will nevertheless come at the expense of jurisdictions that can often ill-afford such losses, either nutritionally, ${ }^{56}$ economically, ${ }^{57}$ industrially ${ }^{58}$ or biologically. ${ }^{59}$ Indeed, such adjustments are projected to be most acute in the Tropics, ${ }^{60}$ South Pacific $^{61}$ and East Asia. ${ }^{62}$ As Dubik et al. observe, the 'geographic movement of resources across political boundaries has important implications for whether and how fishers "follow the fish", the potential social impacts of fish and fishery shifts, and governance response' ${ }^{63}$ In this respect, concerns have already been raised over the scope for both legal ${ }^{64}$ and physical ${ }^{65}$ conflict over shifting fisheries resources.

Despite these present and future trends, the core framework of the law of the sea provides few clear answers to the governance challenges posed by shifting stocks. There is an evident disconnect between legal regimes concerned with climate change on the one hand, and oceans governance on the other. Interactions between these two frameworks have been 'muted at best $^{66}$ and primarily confined to the realms of soft law, ${ }^{67}$ while the marine sphere has been regularly marginalised in multilateral efforts to confront climate change. ${ }^{68}$ Similarly, as products of their respective eras, climate change and associated processes such as acidification are not directly considered within the terms of the LOSC or its current Implementation Agreements. This is particularly true of the UNFSA, whose provisions make no express mention of climate change, while as noted below, RFMOs have also proved slow to embrace this as a core concern. Nevertheless, certain provisions of the UNFSA could be read expansively to promote a degree of further attention towards these issues. Notably, parties recognise the need to 'assess impacts of fishing, other human activities and environmental factors on target stocks ${ }^{69}$ as an operative principle, while in applying the precautionary approach to fisheries, states are to take into account 'existing and predicted oceanic, environmental and socio-economic conditions ${ }^{170}$ in reviewing uncertainties related to fishing. These are nevertheless permissively and vaguely framed and provide little compulsion to

\footnotetext{
${ }^{55}$ Cheung, Watson and Pauly (n.47).

${ }^{56}$ CD Golden et al., 'Fall in Fish Catch Threatens Human Health' (2016) 534 Nature 317.

${ }^{57}$ EH Allison et al., 'Vulnerability of National Economies to the Impacts of Climate Change on Fisheries' (2009) 10 Fish and Fisheries 173.

${ }^{58}$ LCL Teh and UR Sumaila, 'Contribution of Marine Fisheries to Worldwide Employment' (2013) 14 Fish and Fisheries 77.

${ }^{59}$ M Barange et al., 'Impacts of Climate Change on Marine Ecosystem Production in Societies Dependent on Fisheries' (2014) 4 Nature Climate Change 211.

${ }^{60}$ WWL Cheung et al., 'Large-Scale Redistribution of Maximum Fisheries Catch Potential in the Global Ocean under Climate Change' (2010) 16 Global Change Biology 24, 30-31.

${ }^{61}$ Blasiak (n.51).

${ }^{62}$ CM Free et al., 'Impacts of Historical Warming on Marine Fisheries Production' (2019) 363 Science 979.

${ }^{63}$ BA Dubik et al., 'Governing Fisheries in the Face of Change: Social Responses to Long-term Geographic Shifts in a U.S. Fishery' (2019) 99 Marine Policy 243, 244.

${ }^{64}$ Pinsky (n.2); J Spijkers and WJ Boonstra, 'Environmental Change and Social Conflict: The Northeast Atlantic Mackerel Dispute' (2017) 17 Regional Environmental Change 1835.

${ }^{65}$ J Spijkers et al., 'Marine Fisheries and Future Ocean Conflict' (2018) 19 Fish and Fisheries 798.

${ }^{66} \mathrm{C}$ Redgwell, 'Treaty Evolution, Adaptation and Change: Is the LOSC 'Enough' to Address Climate Change Impacts on the Marine Environment?' (2019) 34 International Journal of Marine and Coastal Law 440, 453.

${ }^{67}$ KN Scott, 'Ocean Acidification: A Due Diligence Obligation under the LOSC' (2020) 35 International Journal of Marine and Coastal Law 1, 25.

${ }^{68}$ R Rayfuse, 'Addressing Climate Change Impacts in Regional Fisheries Management Organizations' in Caddell and Molenaar (n.9) 247, 247-248.

${ }^{69}$ Article 5(d).

70 Article 6(3)(e). Parties may also contemplate emergency measures where a 'natural phenomenon has a significant adverse impact on the status of straddling fish stocks or highly migratory fish stocks' (Article 6(7)), although such measures must be temporary and it remains questionable whether anthropogenically driven climate change constitutes a 'natural phenomenon' under this construction.
} 
address stock shifts as a regulatory priority. Ultimately, even the most activist interpretations of the UNFSA acknowledge that there are formidable obstacles to its ability to promote greater accountability and mitigative relief for the impacts of climate change, ${ }^{71}$ and strong reservations remain over the ability of such instruments to be manipulated into more ecologically crusading territory. ${ }^{72}$

Likewise, the LOSC is essentially silent on this issue, although its environmental provisions are being (re-)interpreted with increasing dynamism to integrate climate change concerns more explicitly within the mandate of a living instrument. ${ }^{73}$ Of its specific fisheries provisions, only Article 62(3) offers - albeit indirectly - a potential basis to address a prospective change in the location of fisheries resources, by requiring a coastal state to consider ' all relevant factors, including, inter alia ... the need to minimize economic dislocation in States whose nationals have habitually fished in the zone or which have made substantial efforts in research and identification of stocks'. This commitment was originally intended to mitigate the impact upon fleets that had regularly fished in locations that, prior to the recognition of the EEZ concept under the LOSC, had constituted areas of high seas and had now been repatriated as a new zone of national jurisdiction. In principle, Article 62(3) balances the 'loss' of these fish to the global community by requiring the coastal state to share that portion of the TAC that is surplus to its domestic nutritional requirements. In so doing, this provision applies non-exhaustive and nonhierarchical criteria to guide the allocation of any surplus, although few clear principles beyond the economic self-interest of the coastal state appear to have influenced the national application of Article 62(3) in practice.

The malleability of Article 62(3) in addressing changing fishing patterns has received little consideration to date. The current direction of judicial travel suggests a narrow interpretation of the coastal state's obligations towards interested foreign fishers, at least in the context of those claiming to have fished 'habitually' within the EEZ. ${ }^{74}$ Even so, there are indications that individual coastal states may be prepared to interpret this obligation in a more inclusionary manner, albeit guided by financial or political advantage. One notable context is the post-Brexit position of fishing vessels flagged to the remaining Member States of the European Union, which can demonstrate a long-standing presence in the EEZ of the UK through their participation in the Common Fisheries Policy and may thus advance a tenable case for having met the requirements of this provision. Although fisheries negotiations in the Brexit process are likely to remain a complex and inflammatory issue, the UK government suggested at an early stage that it was receptive to this interpretation of Article 62(3), which has been advanced by a number of EU fishing interests. ${ }^{75}$ Nevertheless, this may be alternatively viewed as

\footnotetext{
${ }^{71}$ WCG Burns, 'A Voice for the Fish? Climate Change Litigation and Potential Causes of Action for Impacts under the United Nations Fish Stocks Agreement' (2008) 11 Journal of International Wildlife Law and Policy 30, 55-62.

72 J Grote Stoutenberg, 'Through the Back-Door: The Limits of the UN Law of the Sea Convention's Usefulness as a Tool to Combat Climate Change' in C Scofield, S Lee and M-S Kwon (eds), The Limits of Maritime Jurisdiction (Leiden, Brill, 2014) 679, 685-686.

73 See A Boyle, 'Litigating Climate Change under Part XII of the LOSC' (2019) 34 International Journal of Marine and Coastal Law 458, 463-469; on the LOSC as an organic regime, see J Barrett, 'The UN Convention on the Law of the Sea: A "Living" Treaty?' in J Barrett and R Barnes, Law of the Sea: UNCLOS as a Living Treaty (London, BIICL, 2016) 1.

${ }^{74}$ South China Sea Arbitration (Philippines v. China), Award of 12 July 2016, para 804 (noting that the EEZ regime of the LOSC has essentially rescinded previous entitlements, hence a coastal state's decision to allow access on the basis of national legislation, bilateral arrangements or through an RFMO would be 'commendable' but not obligatory).

${ }^{75}$ House of Lords European Union Committee, Eighth Report of Session 2016-17; Brexit Fisheries (reproduced at https://publications.parliament.uk/pa/ld201617/ldselect/ldeucom/78/78.pdf.). This may however be further
} 
reflecting a sense of realpolitik, where a coastal state accustomed to making accommodations for particular fishers chooses to maintain access to its EEZ in the unique context of withdrawal from a regional economic integration organisation and with fishing entitlements leveraged against a series of broader negotiating objectives. Moreover, this is not reflective of the position of states attempting to gain access to a stock that has translocated into a neighbouring area of national jurisdiction.

The South China Sea award only addressed the position of pre-existing fishing activities. The second and alternative prong of Article 62(3) concerning those who have materially contributed to the development of a fishery, would appear to offer more assistance to a state seeking access to a stock that has started to shift out of its own EEZ and into that of another. In this instance, it would be open to the state losing fish to argue that it had made the requisite efforts in researching and identifying the stock by previously managing those resources in its own jurisdictional waters. In such a case, the state gaining fish would in principle be required to consider this in determining access to any surplus. This does not guarantee access to the displaced fish, however: there may be no surplus to distribute, a shifting stock that has been previously unfished in these waters might instead be treated as a 'new' fishery (which, as observed below, would be subject to minimal catches and more restrictive oversight), there may be little commercial interest in permitting access or, indeed, the relevant authorities may validly consider that any economic dislocation has ultimately been minimal. States seeking a more privileged degree of access to fish based on the circumstances of Article 62(3) therefore appear best advised to pursue a distinct bilateral arrangement with the other state in question. ${ }^{76}$ Ultimately, this scenario will be optimally resolved through far-sighted and adjustable allocative arrangements between the states in question, ${ }^{77}$ although as noted below few such examples exist at present.

\section{Shifting Stocks and the Pre-emptive Management of Fisheries Resources}

Notwithstanding concerns over the lack of express consideration for the implications of climate change within the broad fisheries framework of the LOSC, a number of legal instruments and regimes have developed proactive and valuable mechanisms with the scope to address some of the issues raised by distributional shifts in fish stocks. In this regard, two broad contexts are especially relevant. Firstly, an array of provisions and policies have been elaborated to regulate the establishment of 'new' fisheries, which provides a precautionary and graduated basis to manage a potential influx of commercially attractive new species. Secondly, states have demonstrated their capacity to negotiate pioneering legal instruments and approaches to govern areas in which commercial fishing remains a theoretical proposition at present but may become more tenable in future decades due to climate-driven stock shifts.

\section{The regulation of new fisheries}

\footnotetext{
complicated by jurisdictional turf-wars between the various devolved administrations of the UK in exercising their respective fisheries competences within those parts of the UK EEZ under their respective control: see R Churchill, 'They're Scotland's Fish! Implications for Brexit for Scots Fisheries Law' (2018) 22 Edinburgh Law Review 110.

${ }^{76}$ S Allen, 'The Jurisprudence of Artisanal Fishing Revisited' in S Allen, N Bankes and Ø Ravna, The Rights of Indigenous Peoples in Marine Areas (Oxford, Hart, 2019) 97, 116.

77 Pinsky (n.2); KL Oremus et al., 'Governance Challenges for Tropical Nations Losing Fish Species due to Climate Change’ (2020) 3 Nature Sustainability 277.
} 
Fish stocks that have been displaced across international boundaries due to changing ocean conditions may represent a resource that has been previously unexploited within that jurisdictional area. Individual states are now increasingly able to contemplate the sustained harvesting of species that have historically had a fleeting or inconsistent presence in their national waters or were not formerly available in sufficient numbers to constitute an economically viable fishery. ${ }^{78}$ Traditionally, international law has been slow to restrain a collective frontier mentality towards unregulated marine living resources, ${ }^{79}$ which has inflicted considerable damage upon fish stocks in locations subject to previously limited oversight, notably in areas beyond national jurisdiction ${ }^{80}$ and the deep-sea environment. ${ }^{81}$ Prior to the adoption of the UNFSA, the pursuit of new fishing opportunities had also been subject to minimal regulation. Since the mid-1990s, however, a discernible set of rules and principles has emerged to regulate new fisheries, ${ }^{82}$ which has provided a valuable management tool to address adjustments in fishing patterns and practices caused inter alia by shifting stocks.

The regulation of emerging fisheries is now an integral part of the precautionary approach to fisheries management promoted under the UNFSA. At a preliminary stage in the negotiations it was recognised that there was a strong commercial and nutritional interest inherent in promoting alternative fishing opportunities, although such activities came with a significant degree of attendant scientific uncertainty and ecological risk. ${ }^{83}$ Historically, new fisheries were instituted with little data - or thought - as to the prospective impacts of fishing on the target stock, non-target species and associated ecosystems, frequently resulting in a pattern of boomand-bust as lasting damage was inflicted upon finite resources before meaningful regulation could be applied to these activities. The UNFSA fills this lacuna by imposing restrictions upon the parameters of intended new fisheries, envisaging that conservation measures will be applied and subsequently eased as a fuller picture of the impacts of such fisheries progressively emerges. To this end, Article 6(6) provides:

'[f]or new and exploratory fisheries, States shall adopt as soon as possible cautious conservation and management measures, including, inter alia, catch limits and effort limits. Such measures shall remain in force until there are sufficient data to allow assessment of the impact of the fisheries on the long-term sustainability of the stocks, whereupon conservation and management measures based on that assessment shall be

\footnotetext{
${ }^{78}$ WWL Cheung et al., 'Review of Climate Change Impacts on Marine Fisheries in the UK and Ireland' (2012) 22 Aquatic Conservation: Marine and Freshwater Ecosystems 368, 374 (noting lucrative new fishing opportunities for stocks such John Dory, anchovy and red mullet that have expanded their distribution into UK waters due to changing ocean conditions).

79 A Merrie et al., 'An Ocean of Surprises - Trends in Human Use, Unexpected Dynamics and Governance Challenges in Areas beyond National Jurisdiction' (2014) 27 Global Environmental Change 19, 26

${ }^{80}$ EJ Molenaar, 'Addressing Regulatory Gaps in High Seas Fisheries' (2005) 20 International Journal of Marine and Coastal Law 533.

${ }^{81}$ R Caddell, 'Deep-Sea Bottom Fisheries and the Protection of Seabed Ecosystems: Problems, Progress and Prospects' in C Banet (ed), The Law of the Seabed: Access, Uses, and Protection of Seabed Resources (Leiden/Boston, Brill, 2020) 255.

${ }^{82}$ See further R Caddell, 'Precautionary Management and the Development of Future Fishing Opportunities: The International Regulation of New and Exploratory Fisheries' (2018) 33 International Journal of Marine and Coastal Law 199.

${ }^{83}$ FAO, The Precautionary Approach to Fisheries with Reference to Straddling Fish Stocks and Highly Migratory Fish Stocks; Document A/CONF.164/INF/8, 26 January 1994, para 90; reproduced in J-P Lévy and GG Schram, United Nations Conference on Straddling Fish Stocks and Highly Migratory Fish Stocks: Selected Documents (The Hague, Kluwer, 1996) 574.
} 
implemented. The latter measures shall, if appropriate, allow for the gradual development of the fisheries.'

The concept of a 'new' or an 'exploratory' fishery is not elaborated further within the UNFSA, and indeed remains definitionally inconsistent across a range of regulatory bodies. Article 6(6) was heavily influenced by the contemporaneous elaboration of parallel policies by the Commission on the Conservation of Antarctic Marine Living Resources (CCAMLR), which remains the most prominent regulator of these specific fisheries. CCAMLR's more ostensible ecosystem-based mandate ${ }^{84}$ renders it unique within the firmament of international fisheries regulators ${ }^{85}$ and prior to the adoption of the UNFSA it was arguably the only body with the requisite authority to pioneer a more conservation-oriented approach to fisheries. ${ }^{86}$ While the UNFSA provides little guidance on the implementation of this requirement, its value lies in its guiding influence as a template for the competences of subsequent RFMOs. In this respect, the post-UNFSA RFMOs have included express provision for the regulation of new and exploratory fisheries within their constituent treaties - notably the Western and Central Pacific Fisheries Committee (WCPFC), ${ }^{87}$ South-East Atlantic Fisheries Organisation (SEAFO), ${ }^{88}$ Southern Indian Ocean Fisheries Agreement (SIOFA), ${ }^{89}$ South Pacific Regional Fisheries Management Organisation (SPRFMO) ${ }^{90}$ and the North Pacific Fisheries Commission $(\mathrm{NPFC})^{91}$ - which may not have occurred as readily otherwise.

The first formal regulatory expectations for states seeking to develop new fisheries beyond national jurisdiction were formulated by CCAMLR in $1991,{ }^{92}$ applying to fisheries for which 'information on distribution, abundance, demography, potential yield and stock identity from comprehensive research/surveys or exploratory fishing' or catch and effort data had not been submitted. Where a new fishery is proposed, the Member in question is required to provide notice of its intent to fish three months in advance of the next regular CCAMLR meeting. ${ }^{93}$ The applicant is also required to submit a Fishery Operation Plan, which will include a full outline of the nature of the new fishery, its location, target species, gear to be used and proposed minimum catch levels, alongside biological information on the target species, potential bycatches, comparable data from similar fisheries and possible impacts upon vulnerable marine ecosystems, especially benthic communities. ${ }^{94}$ Proposals are contingent upon a commitment to implement a Data Collection Plan that may be established for that fishery by the Scientific Committee; such fishing opportunities may then only be undertaken by vessels that are suitably

\footnotetext{
${ }^{84}$ Convention for the Conservation of Antarctic Marine Living Resources; 1329 UNTS 47 (Article II).

${ }^{85}$ With a far broader ecological mandate than most classical fisheries bodies, CCAMLR is considered to be 'more than an RFMO': R Billé et al., Regional Oceans Governance: Making Regional Seas Programmes, Regional Fishery Bodies and Large Marine Ecosystem Mechanisms Work Better Together (Nairobi, UNEP, 2016) 29-34.

${ }^{86}$ See further EJ Molenaar, 'CCAMLR and Southern Ocean Fisheries' (2001) 16 International Journal of Marine and Coastal Law 465.

${ }^{87}$ Convention on the Conservation and Management of Highly Migratory Fish Stocks in the Western and Central Pacific Ocean 2000; 2275 UNTS 43, (Article 6(5)).

${ }^{88}$ Convention on the Conservation and Management of Fishery Resources in the South-East Atlantic Ocean 2001; 2221 UNTS 189 (Article 20).

89 Southern Indian Ocean Fisheries Agreement 2006 (available at http://www.fao.org/fishery/rfb/siofa/en); (Article 6).

${ }^{90}$ Convention on the Conservation and Management of High Seas Fishery Resources in the South Pacific Ocean 2009; [2012] ATS 28 (Article 22).

${ }^{91}$ Convention on the Conservation and Management of High Seas Fisheries Resources in the North Pacific Ocean 2011 (available at http://npfc.r-cms.jp/About Convention/). (Articles 3 and 7).

${ }^{92} \mathrm{CM} 31 / \mathrm{X}$; this was subsequently reformulated as CM 21-01, which applies today.

${ }^{93}$ CM 21-01; Article 3(i).

${ }^{94}$ Article 3(ii).
} 
equipped and configured to comply with all relevant conservation measures. Once a new fishery has been instituted, it becomes an 'exploratory fishery' in subsequent years. Exploratory fisheries retain this status unless and until sufficient information is forthcoming to evaluate the distribution, abundance and demography of the target species so as to provide an estimate of the fishery's potential yield, to review the impacts of the fishery upon dependent and related species and to allow the Scientific Committee to formulate and provide advice to the Commission on appropriate harvest catch levels, as well as effort levels and fishing gear, where appropriate. ${ }^{95}$

New and exploratory fisheries therefore operate on a quid pro quo whereby a limited degree of fishing is permitted in exchange for the assiduous collection of agreed data on both the stock structure and the ecosystem impacts of fishing. Participation in new and exploratory fisheries in the CCAMLR Area is conditional upon a record of good conduct, with access denied to any vessel that has been listed as having participated in Illegal, Unreported or Unregulated (IUU) fishing, ${ }^{96}$ while exploratory privileges do not appear to generate preferential access to these resources if the fishery is later recategorized as a commercial enterprise. ${ }^{97}$

Seven exploratory fisheries are currently active within the CCAMLR Area, most having been established in the late 1990s, although none have graduated through the Article 6(6) process and transitioned into commercial fisheries. Although compliance with the broad requirements of new and exploratory fisheries has been generally high, meeting the data collection requirements incumbent in the CCAMLR rules has proved to be a protracted and challenging process. Participation in these endeavours has been variable and relatively few have yet returned the volumes of data conducive to a relaxation of these conditions. ${ }^{98}$ This is partly attributable to the operational and financial difficulties inherent in undertaking developmental fishing in remote and hostile areas of the Southern Ocean, although concerns have been expressed that fishers have prioritised the collection of data concerning stock structures over the environmental impacts of harvesting, or have failed to return necessary data from these activities. ${ }^{99}$ CCAMLR has traditionally declined to sanction poor data collection practices within exploratory fisheries, although this has clearly tested the patience of individual participants who have advocated a more punitive approach. ${ }^{100}$ Only one such fishery, located in the Ross Sea, has approached the threshold requirements for a review of its exploratory status, although political approval has proved to be more elusive. Nevertheless, considerable scientific misgivings have been expressed as to the lack of adaptive capacity of the system and deficiencies in ecosystem monitoring, ${ }^{101}$ and any eventual transition to commercial management would seemingly involve little easing of the current regulatory conditions.

These shortcomings aside, the approach taken to new and exploratory fisheries has provided a practical mechanism to help mitigate the scientific uncertainty inherent in shifting distributional patterns and an extension of fishing effort into new areas. The CCAMLR model

\footnotetext{
${ }^{95}$ CM 21-02, para 1(ii).

${ }^{96}$ CM 21-01 (para 9) and CM 21-02 (para 13).

${ }^{97}$ Caddell (n.82) 223-226.

98 Ibid., 228-234.

${ }^{99}$ CCAMLR, Report of the Thirty-Fourth Meeting of the Commission (CCAMLR-XXXIV), para 9.19.

${ }^{100}$ Notably the US: CCAMLR, Report of the Twenty-Ninth Meeting of the Commission (CCAMLR-XXIX), para 12.37.

101 PA Abrams et al., 'Necessary Elements of Precautionary Management: Implications for the Antarctic Toothfish’ (2016) Fish and Fisheries 1, 14-17.
} 
has been incorporated largely verbatim into the practices of other RFMOs, ${ }^{102}$ while similar approaches have been adopted in national policies, applying principles - if not necessarily terminology - reminiscent of the Antarctic arrangements. ${ }^{103}$ This provides a precautionary basis for addressing new stocks that may be unfamiliar to the RFMO in question - an issue of particular pertinence to the high seas, where less than five percent of fish species are currently subject to scientific assessment ${ }^{104}$ - and can plug a potential regulatory vacuum pending more measured consideration. ${ }^{105}$ Indeed, the regime of exploratory fisheries has provided a helpful mechanism to partially manage the ingress of particular species - and fishers - across the jurisdictional boundaries of RFMOs pending more formalised cooperation between governing bodies, as illustrated by the relationship between CCAMLR and the Commission for the Conservation of Southern Bluefin Tuna (CCSBT) discussed further below.

\section{Pre-emptive fisheries management}

As noted above, projections overwhelmingly indicate a concerted Poleward shift of marine living resources due to climate change. A number of northerly states have experienced an influx of fish and other marine species in recent years, raising expectations that the Arctic may constitute the ultimate destination for a number of displaced stocks. ${ }^{106}$ While the extent of this potential biomass windfall remains uncertain - indeed, changing ocean conditions may ultimately create as many new biological impediments to Arctic colonisation as they remove ${ }^{107}$ - this phenomenon has played out against a backdrop of increasing industrial ambition for the Arctic, as the receding ice coverage has generated tantalising economic opportunities and attracted the attention of a growing number of enterprising states from within and beyond the region.

Arguably the most ambitious regulatory initiative towards addressing shifting fish stocks has been the development of arrangements towards managing future commercial fisheries in the Central Arctic Ocean. A universally accepted definition of the 'Arctic' remains elusive, ${ }^{108}$ and the array of states most appropriately entitled to drive regulatory processes for these waters remains subject to enduring controversy. ${ }^{109}$ Although a series of bodies technically exercise fisheries competence within parts of the areas beyond national jurisdiction in the Arctic region, this location has remained studiously unregulated to date. ${ }^{110}$ Between 2008 and 2015, the

\footnotetext{
102 Notably SPRFMO, which borders the CCAMLR Area and has sanctioned exploratory fishing in adjacent areas essentially conducted by the same operators, and SEAFO.

${ }^{103}$ See the New Emerging Fisheries Policy of Canada, first instituted in 1996.

${ }^{104}$ G Ortuño Crespo et al., 'High-seas Fish Biodiversity is Slipping through the Governance Net' (2019) 3 Nature Ecology and Evolution 1273, 1275.

${ }^{105}$ Rayfuse (n.68) 254.

${ }^{106}$ See MS Wisz et al., 'Arctic Warming Will Promote Atlantic-Pacific Fish Interchange' (2015) 5 Nature Climate Change 261, 262 and JS Christiansen, CW Mecklenburg and OV Karamushko, 'Arctic Marine Fishes and their Fisheries in the Light of Global Change' (2014) 20 Global Change Biology 352, 354-356.

${ }^{107}$ VWY Lam, WWL Cheung and UR Sumaila, 'Marine Capture Fisheries in the Arctic: Winners or Losers under Climate Change and Ocean Acidification?' (2016) 17 Fish and Fisheries 335, 348-349.

108 AG Oude Elferink, EJ Molenaar and DR Rothwell, 'The Regional Implementation of the Law of the Sea and the Polar Regions' in EJ Molenaar, AG Oude Elferink and DR Rothwell, The Law of the Sea and the Polar Regions: Interactions between Global and Regional Regimes (Leiden/Boston, Brill, 2013) 1, 9-11.

${ }^{109}$ K Dodds, "Real Interest"”? Understanding the 2018 Agreement to Prevent Unregulated High Seas Fisheries in the Central Arctic Ocean' (2019) 10 Global Policy 542.

${ }^{110}$ EJ Molenaar, 'International Regulation of Central Arctic Ocean Fisheries' in MH Nordquist, JM Moore and R Long (eds), Challenges of the Changing Arctic: Continental Shelf, Navigation, and Fisheries (Brill, Leiden/Boston, 2016) 429, 432-433.
} 
coastal states comprising the 'Arctic Five' (Canada, Denmark, Norway, Russia and the US) convened a series of meetings on the prospective regulation of Arctic fisheries, resulting in a Declaration Concerning the Prevention of Unregulated High Seas Fishing in the Central Arctic Ocean, ${ }^{111}$ pledging to apply the precautionary approach to develop interim measures to deter unregulated fishing. ${ }^{112}$ Between 2015 and 2018 they were joined by China, the EU, Iceland, Japan and South Korea in a 'Broader Process' of negotiations towards elaborating a more formalised basis to pursue this objective, culminating in the conclusion of the Agreement to Prevent Unregulated High Seas Fisheries in the Central Arctic Ocean on 3 October 2018. ${ }^{113}$

The CAOFA is a concise document that recognises that although "commercial fishing is unlikely to become viable in the high seas portion of the central Arctic Ocean in the near future', the ecosystem is changing 'due to climate change and other phenomena', thereby justifying precautionary consideration of the present and prospective fish stocks of the region. ${ }^{114}$ The objective of the Agreement is therefore to "prevent unregulated fishing in the high seas portion of the central Arctic Ocean through the application of precautionary conservation and management measures as part of a long-term strategy to safeguard healthy marine ecosystems and to ensure the conservation and sustainable use of fish stocks'. ${ }^{115}$ The CAOFA is projected to apply to all fish other than sedentary species recognised under Article 77 of the $\operatorname{LOSC}^{116}$ in the waters of the Arctic beyond which states exercise fisheries jurisdiction. ${ }^{117}$ The Agreement is scheduled to remain in force for an initial period of 16 years and is extendable for five-year periods thereafter, until replaced with a more permanent regional fisheries body if required. ${ }^{118}$ Participation in the COAFA is currently restricted to the ten initial negotiating parties, although other states with a 'real interest' may be invited at a later point. ${ }^{119}$

The Agreement restricts all commercial fishing activities in these waters pending the elaboration of interim measures or the adoption of specific conservation and management measures by any 'regional or subregional fisheries management organizations or arrangements, that have been or may be established and are operated in accordance with international law to manage such fishing in accordance with recognized international standards'. ${ }^{120}$ The parties also commit to instituting a Joint Program of Scientific Research and Monitoring (JPSRM) "with the aim of improving their understanding of the ecosystems of the Agreement Area and, in particular, of determining whether fish stocks might exist in the Agreement Area now or in the future that could be harvested on a sustainable basis and the possible impacts of such fisheries on the ecosystems of the Agreement Area'. ${ }^{121}$ While commercial activities are currently precluded, the parties nonetheless contemplate the pursuit of two distinct categories of fishing

\footnotetext{
${ }^{111}$ Reproduced at https://www.regjeringen.no/.../ud/.../declaration-on-arctic-fisheries-16-july-2015.pdf.

112 VJ Schatz, A Proelss and N Liu, 'The 2018 Agreement to Prevent Unregulated High Seas Fisheries in the Central Arctic Ocean: A Critical Analysis’ (2019) 34 International Journal of Marine and Coastal Law 195, 204209.

113 Reproduced at http://publications.europa.eu/resource/cellar/f075cd03-46f3-11e9-a8ed01aa75ed71a1.0006.03/DOC_1 ('CAOFA').

114 Preamble.

115 Article 2.

116 Article 1(b).

117 Article 1(a). This somewhat unusual formulation represents an acknowledgement of the contested fisheries sovereignty in the waters around the Svalbard archipelago.

118 Article 13.

${ }^{119}$ Articles 9 and 10 .

${ }^{120}$ Article 3(1). This construction recognises that existing fisheries bodies may have a future role to play in this respect.

121 Article 4(2).
} 
in these waters. In the first instance, a volume of exploratory fishing may be conducted under specific conservation and management measures to be elaborated by the parties. ${ }^{122}$ Alternatively, the parties 'are encouraged to' undertake research fishing under the JPSRM, provided that it 'does not undermine the prevention of unregulated commercial and exploratory fishing and the protection of healthy marine ecosystems', with the parties further encouraged to inform each other of such activities. ${ }^{123}$ Concerns have nevertheless been raised that this provision could be abused in a manner reminiscent of the problems experienced with scientific whaling. ${ }^{124}$ Indeed, the distinction between 'research' and 'exploratory' fishing is fundamentally artificial - both involve restricted fishing activities with specified methodologies and the reporting of an agreed volume of scientific data - although there has been a recent trend within RFMOs towards maintaining multiple nomenclature, ${ }^{125}$ to the interpretive detriment of policies towards non-commercial fisheries.

Given that the Agreement has not yet entered into effect, fishing arrangements in these waters remains a point of conjecture. It may be considered likely that the regulation of non-commercial fishing will mirror that of CCAMLR to at least some degree, given its long-standing experience in managing such fisheries in analogous Polar waters, its influence on such policies in other RFMOs and that most of the prospective CAOFA parties are also seasoned CCAMLR participants. Conversely, the challenges experienced in regulating non-commercial fisheries in the Antarctic are also likely to be replicated in these waters. Even so, the CAOFA represents a unique approach to changing marine ecosystems by elaborating pre-emptive controls and imposing a precautionary ethos $a b$ initio. It is also one assisted by the current lack of entrenched interests ${ }^{126}$ and formidable commercial and biological barriers to large-scale fishing, which are not widely replicated in other areas of the ocean. Nevertheless, the economic temptations of shifting stocks in the long-term future may represent a significant challenge to this regulatory approach. Indeed, notwithstanding these arrangements, Russia has recently announced its intention to establish a commercial fishery for pollock within the Chukchi Sea, with biomass having expanded dramatically in these waters due to climate change, ${ }^{127}$ which suggests that future commercial ambition will increasingly chafe against laudably professed pre-emptive intentions.

\section{RFMOs and Climate Change}

RFMOs remain the preferred vehicle through which the conservation and management of fish stocks, especially straddling and highly migratory stocks, is to be pursued. ${ }^{128}$ To date, a loose constellation of fisheries management bodies has been established in many - but by no means

\footnotetext{
${ }^{122}$ Article 3(3). Exploratory fishing is defined as 'fishing for the purpose of assessing the sustainability and feasibility of future commercial fisheries by contributing to scientific data relating to such fisheries': Article 1(e). ${ }^{123}$ Article 3(4).

${ }^{124}$ Schatz, Proelss and Liu (n.112) 226.

125 Caddell (n.82) 233-234.

${ }^{126}$ R Rayfuse, 'Regulating Fisheries in the Central Arctic Ocean: Much Ado About Nothing?' in N Vestergaard, BA Kaiser, L Fernandez and JN Larsen (eds), Arctic Marine Resource Governance and Development (Heidelberg, Springer, 2018) 35, 48-49.

${ }^{127}$ Y Rosen, 'Russia is Poised to Open the First-Ever Commercial Pollock Fishery in Chukchi Sea', The Barents Observer, 25 June 2020.

${ }^{128}$ UNFSA, Articles 8-14. This position has been reinforced by successive Resolutions of the UN General Assembly as the primary means through which states give effect to the duty of cooperation established under the LOSC and UNFSA: Y Takei, Filling Regulatory Gaps in High Seas Fisheries: Discrete High Seas Fish Stocks, Deep-sea Fisheries and Vulnerable Marine Ecosystems (Leiden/Boston, Brill, 2013) 67.
} 
all - areas of the global oceans to regulate particular stocks. Despite this coverage, however, consideration of climate change impacts upon fisheries resources has been patchy and underwhelming. Indeed, climate change has generally transpired to be a peripheral concern for most bodies and even the most ecologically prominent fisheries actors have struggled to find the far-sighted political consensus necessary to address these problems proactively.

\section{Shifting stocks and RFMO interactions}

Mirroring current concerns over the propensity for changing ocean conditions to displace fish stocks across the boundaries of coastal states, RFMOs may also receive an influx of prospective new species into areas under their competence or, conversely, experience a steady displacement of stocks into the waters of a neighbouring RFMO or an unregulated area of high seas. As with individual states, stocks that are redistributed across frontiers of legal responsibility face the risk of over-exploitation and dysfunctional oversight due to managerial turf-wars between regulatory regimes. Nevertheless, while analogous to a transboundary shift between EEZs, distributional adjustments of stocks across the frontiers of RFMOs raise markedly different legal issues. Indeed, as astutely outlined in this context by EU fisheries representatives, a proprietary interest in the stock is absent given that RFMOs are forums that provide a foundation for their members to discharge their cooperation and conservation obligations prescribed under the LOSC, rather than 'entities with original exclusive rights similar to the ones enjoyed by sovereign States in sea areas under national fisheries jurisdiction' ${ }^{129}$

The regulatory difficulties inherent in distributional shifts of commercially significant fish stocks were first encountered in the North Atlantic in the late 1990s in the context of oceanic redfish, a deep-sea fish that had been managed exclusively by the North-East Atlantic Fisheries Commission (NEAFC) since 1982. ${ }^{130}$ By the late 1990s it was apparent that warming waters had displaced a sizeable contingent of redfish into the neighbouring area of competence of the North Atlantic Fisheries Organisation (NAFO), and a number of enterprising states sought to avail themselves of opportunities to maximise access to the stock. ${ }^{131}$ While it remained unclear at the time whether this displacement was a temporary aberration or a more permanent shift, in 2001 the two bodies agreed on a pre-emptive system of joint management whereby NEAFC has continued to set the TAC, of which a portion is allocated to NAFO to be distributed among its membership. In this manner, the parties to two RFMOs with broadly similar memberships and conservation obligations were able to broker a pragmatic solution to a then unprecedented issue, which has subsequently facilitated further collaboration on common operational matters. ${ }^{132}$

More recently, concerns have been raised by the changing distribution patterns of tuna, which have shifted Poleward $6.5 \mathrm{~km}$ per decade in the northern hemisphere and $5.5 \mathrm{~km}$ poleward in

\footnotetext{
${ }^{129}$ NAFO, Report of the NAFO/NEAFC Working Group on Oceanic Redfish; Document NAFO/FC/Doc.01/3, 10. 130 Redfish nevertheless raised regulatory complications since the commencement of this fishery and a combination of scientific uncertainty and economic demand meant that catches have long been considered unsustainable: RR Churchill, 'Managing Straddling Fish Stocks in the North-East Atlantic: A Multiplicity of Instruments - but How Effective a Management?' in OS Stokke (ed), Governing High Sea Fisheries: The Interplay of Global and Regional Regimes (Oxford, Oxford University Press, 2001) 235, 255-262.

131 A Thomson, 'The Management of Redfish (Sebastes mentella) in the North Atlantic Ocean - A Stock in Movement' in FAO Fisheries Report No. 695 (Rome, FAO, 2003) 192, 196.

132 OS Stokke, 'Management Options for High Seas Fisheries: Making Regime Complexes More Effective' in Caddell and Molenaar (n.9) 51, 68.
} 
the southern hemisphere. ${ }^{133}$ Tuna have historically attracted the most sustained degree of regional regulation and opportunities for collaboration have been pursued under the Kobe Process between the array of RFMOs responsible for these species, even if these bonds are considerably looser than the clustering arrangements and policy alignments characteristic of multilateral environmental agreements. ${ }^{134}$ As was initially mooted in the redfish saga, tuna RFMOs may be better placed to address stock shifts given the 'acquiescence of a regulatory priority for the organisation within which the bulk of a tuna stock occurred' ${ }^{135}$ This is most clearly exemplified by the CCSBT, whose constituent treaty applies to the entirety of the migratory range of this species, rather than to specified geographical coordinates, ${ }^{136}$ and for which other tuna RFMOs have recognised its 'prime responsibility' over any stocks located within their areas of operation. ${ }^{137}$ The precise arrangements for the regulation of southern bluefin tuna in areas under the competence of non-tuna RFMOs has, however, required further negotiation. In 2005, southern bluefin tuna - and, more specifically, the fishing vessels pursuing these fish - were reported in increasing numbers within the CCAMLR Area, ${ }^{138}$ seemingly operating under the misconception that the management policies of the CCSBT overrode those of other organisations regarding such species, ${ }^{139}$ a mindset that CCAMLR wished to correct in a firm, yet collegiate, manner.

Particular concerns were raised that an influx of tuna vessels could encourage an expansion in IUU fishing, an already grievous concern within CCAMLR waters, while also promoting fishing practices that are not in compliance with CCAMLR standards. ${ }^{140}$ In response, the CCSBT contacted CCAMLR seeking formal recognition of the primacy of the CCSBT over these stocks where they occurred within the Southern Ocean. ${ }^{141}$ CCAMLR in return considered that a clearer demarcation of responsibilities ought to be established through an Agreement between the two bodies, notably concerning which organisation's conservation and management measures should be prioritised. In this regard, CCAMLR appears to have been particularly concerned by the scope for seabird bycatches, for which extensive mitigation measures have been developed under its auspices. This was a point of contention for certain CCSBT parties, who argued that compliance with these requirements was disproportionately burdensome given the modest volume of fishing effort for tuna pursued in these waters. ${ }^{142}$

\footnotetext{
${ }^{133}$ M Erauskin-Extramiana et al., 'Large Scale Redistribution of Tuna in a Warming Ocean' (2019) 25 Global Change Biology 2043.

${ }^{134}$ Harrison (n.41) 99; on these latter approaches see Churchill and Ulfstein (n.5).

135 NAFO (n.129) 11.

${ }^{136}$ Convention for the Conservation of Southern Bluefin Tuna 1993; 1819 UNTS 359 (Article 1).

${ }^{137}$ As specified, for instance, by the Indian Ocean Tuna Commission (IOTC) at a preliminary stage in its operation: Report of the First Special Session of the IOTC, para 31; see also IOTC Resolution 98/03 on Southern Bluefin Tuna, which reinforces deference to the CCSBT on the management of these stocks within the IOTC Area, and the WCPFC which, in its Memorandum of Understanding with the CCSBT acknowledges that the CCSBT 'is the appropriate body to develop and implement southern bluefin tuna conservation and management measures': reproduced at https://www.wcpfc.int/doc/wcpfc-ccsbt-memorandum-understanding.

${ }^{138}$ CCAMLR, Report of the Twenty-Fourth Meeting of the Commission (CCAMLR-XXIV), para 15.21.

139 A Serdy, 'Antarctic Fisheries Management' in Molenaar, Oude Elferink and Rothwell (n.108) 217, 236.

${ }^{140}$ R Rayfuse, 'Climate Change and Antarctic Fisheries: Ecosystem Management in CCAMLR' (2018) 45 Ecology Law Quarterly 53, 79.

${ }^{141}$ CCSBT, Report of the Extended Commission of the 12 ${ }^{\text {th }}$ (2005) Annual CCSBT Meeting para 126; see A Hemmings, 'Regime Overlap in the Southern Ocean: The Case of Southern Bluefin Tuna and CCSBT in the CCAMLR Area' (2006) 3 New Zealand Yearbook of International Law 207, 210-213.

${ }^{142}$ CCSBT, Report of the 14 ${ }^{\text {th }}$ Annual CCSBT Meeting, paras 199-200. Tellingly, the CCSBT considered that CCAMLR's divergent approach was attributable to 'a purpose more associated with the protection of a unique environment than the CCSBT, where the purpose of its creation related more to the commercial international exploitation of a high seas fishery': Document CCSBT-EC/0710/12: Relationship with CCAMLR.
} 
CCAMLR nevertheless stood firm on this point, ${ }^{143}$ a position that seems to have prolonged the endorsement of an Agreement that was proposed in 2009, concluded in 2012 and renewed in 2015 and 2019. Pointedly, CCAMLR has insisted upon compliance with its conservation measures, ${ }^{144}$ although the most recent iteration of the Agreement adopts a more collaborative approach, with both bodies pledging to exchange data on fishing effort and practices. ${ }^{145}$ In the interim, tuna fishing in the Southern Ocean was addressed under a hybrid system in which participants in both organisations have agreed to pursue these allocations through the CCSBT, with catches in the CCAMLR Area most appropriately addressed under its regime on new and exploratory fisheries. ${ }^{146}$

\section{RFMOs and the management of shifting stocks}

While RFMOs have managed to broker collaborative arrangements between each other that provide a basis for information sharing and wider commitments towards cooperation - which could prospectively engage issues of future stock shifts and an exchange of pertinent scientific data to aid decision-making processes - few specific policies have emerged under their collective auspices to directly address wider distributional uncertainties created by climate change. Although this may be partly attributable to a lack of homogenous terminologies between organisations which have different means of articulating climate-induced management challenges, the phrase 'climate change' is panoramically considered to refer 'to more general climatic variance than to climate change as a specific phenomenon'. ${ }^{147}$ Indeed, only CCAMLR has adopted a targeted Resolution on climate change to date, a position reflective of its status as 'more than' an RFMO and with a far broader ecological mandate than other fisheries bodies. In 2009, the parties adopted Resolution 30/XVIII on climate change, declaring global climate change to be 'one of the greatest challenges facing the Southern Ocean' and calling for increased consideration of climate change impacts to better inform CCAMLR's management decisions.

To date, however, this appears to have had a limited impact upon fisheries management under CCAMLR. On the one hand, Resolution 30/XVIII has inspired new regulatory developments, that demonstrate a far-sighted approach to fisheries management, albeit in highly specific contexts. One such example is the regulation of fisheries within 'newly-exposed marine areas', whereby new areas of the sea have become accessible following the collapse of segments of the Antarctic ice-shelf. In 2017, CCAMLR established a process for the designation of timelimited Special Areas for Scientific Study in segments of the Agreement Area most vulnerable to ice-melt, based on the regulatory impetus of Resolution 30/XVIII. ${ }^{148}$ Under these arrangements, a limited degree of research fishing may be prospectively pursued subject to broadly similar restrictions to CCAMLR's research and exploratory fisheries conditions. ${ }^{149}$

Nevertheless, further advancements have proved to be a difficult political proposition. This is exemplified by the protracted process towards the establishment of CCAMLR's cornerstone

\footnotetext{
${ }^{143}$ CCAMLR, Report of the Thirty-first Meeting of the Commission (CCAMLR-XXXI), para 9.15

144 Ibid.

145 Agreement between the Commission for the Conservation of Southern Bluefin Tuna and the Commission for the Conservation of Antarctic Marine Living Resources, reproduced at https://www.ccamlr.org/en/system/files/CCSBT_2.pdf.

${ }^{146}$ CCAMLR, Report of the Twenty-fifth Meeting of the Commission (CCAMLR-XXV), para 16.40.

${ }^{147}$ Rayfuse (n.68) 259

${ }^{148}$ CM 24-04.

149 Para 14.
} 
marine protected area (MPA) in the Ross Sea ${ }^{150}$ which also established time-limited restrictions on fishing activities, albeit after numerous years of tortuous negotiations. ${ }^{151}$ More recently, various Members have sought to integrate climate change considerations more centrally within Antarctic fisheries management, as recommended by the most recent Performance Review of CCAMLR in 2017. ${ }^{152}$ This recommendation remains essentially unfulfilled, however: the submission of climate change data within the annual Fishing Reports returned by the Members is considered a 'useful addition', but a strictly voluntary one. ${ }^{153}$ Attempts to update Resolution 30/XVIII in a more ecologically robust manner appear to have met stern political resistance at the most recent CCAMLR Meeting. ${ }^{154}$ Nevertheless, the inability of CCAMLR, the international fisheries actor with the clearest ecological priorities, to broker the requisite political momentum to adopt far-sighted fisheries management in the face of global climate change, suggests little cause for optimism for the policies of other RFMOs. ${ }^{155}$

Such a pessimistic outlook appears eminently justified. More broadly, the periodic Review Conference of the UNFSA has accorded little priority to climate change concerns. Climate change was not even tangentially considered at the first meeting of the Review Conference in 2006, while its subsequent instalments in $2010^{156}$ and $2016^{157}$ viewed this issue in largely unfocused terms, highlighting a general need to further understanding the risks posed to fish stocks by climate change. Similarly, despite a broad trend towards increased cooperation between RFMOs on an individual and collective basis, shifting stocks have received little attention to date. Indeed, the meetings of the Kobe Process have yet not considered this issue at all. ${ }^{158}$ Certain participants have at least noted that this ought to be part of future collective discussions ${ }^{159}$ - and the Kobe Process provides intriguing possibilities to promote cross-RFMO collaborations, with discernible progress having been made through joint working groups on bycatch mitigation and IUU fishing - although it remains to be seen whether this will ultimately translate into tangible activity.

Stock shifts may not yet have unduly occupied the regulatory attentions of RFMOs, but this issue has been independently identified as an issue for future concern within some of the more recent Performance Reviews of these organisations. These processes, conducted by critical friends of the RFMO in question, have resulted in a series of recommendations for governance and management improvements. This is no mere paper exercise, with the outcomes taken seriously by RFMOs, which have subsequently sought to implement meaningful adjustments to their working practices. ${ }^{160}$ For instance, following its second Performance Review, the General Fisheries Commission for the Mediterranean (GFCM) convened an extensive workshop on climate change implications for Mediterranean and Black Sea fisheries in 2017, which identified climate-induced shifts in fish distribution as a future challenge, both from the

${ }^{150}$ CM 91-05.

${ }^{151}$ Rayfuse (n.140) 68-72.

${ }^{152}$ CCAMLR, Second Performance Review of CCAMLR - Final Report of the Panel; Recommendation 6.

${ }^{153}$ CCAMLR, Report of the Thirty-seventh Meeting (CCAMLR-XXXVII), para 8.4.

${ }^{154}$ CCAMLR, Report of the Thirty-eighth Meeting (CCAMLR-38), para 8.14. These evidently divergent views were nevertheless reported with the traditional diplomatic understatement associated with the Antarctic Treaty System.

${ }^{155}$ Rayfuse (n.140) 81; MR Wendebourg, 'Southern Ocean Fishery Management - Is CCAMLR Addressing the Challenges Posed by a Changing Climate?' (2020) 119 Marine Policy (in press).

156 A/CONF.210/2010/7, Outcome I(n).

${ }^{157}$ A/CONF.210/2016/5, Outcome 4.

${ }^{158}$ See further http://www.tuna-org.org/meetingspast.htm.

${ }^{159}$ CCSBT, Performance of the CCSBT 2009-2013, 80.

160 B Haas et al., 'The Influence of Performance Reviews on Regional Fisheries Management Organizations' (2019) 76 ICES Journal of Marine Science 2082, 2089. 
standpoint of governance issues as well as in addressing invasive species. ${ }^{161}$ Similarly, reviews of NAFO and NEAFC - mindful of their previous and current experiences with shifting stocks - have also identified this issue as a matter of future concern. In the context of NAFO, for instance, it was observed that 'climate change may have an impact on distribution patterns of fish stocks with subsequent challenges concerning allocation arrangements of those stocks straddling between Exclusive Economic Zones and the high seas', ${ }^{162}$ for which the Review Panel recommended revisiting the current allocation of new fishing opportunities 'should a change in circumstances justify it'. ${ }^{163}$ The Review Panel of NEAFC also observed that '[m] any of the species regulated by NEAFC appear to be sensitive to climate effects, not only in recruitment variability but species distributions and species overlaps ... controversies regarding changing spatial distributions of migratory species stem in part from fishes responses to climate variations', ${ }^{164}$ recommending that climate effects be considered more explicitly in developing its management programme and that the scientific basis for such approaches be improved. ${ }^{165}$

Identifying the problems associated with climate change and subsequently implementing meaningful outcomes nevertheless remains a significant challenge. Stock shifts and environmental changes are multifaceted phenomena and 'in many situations it remains difficult to disentangle the effects of climate change with those of other anthropogenic influences', ${ }^{166}$ which may inhibit the recognition of such impacts as an operative priority. Meanwhile, it remains highly questionable as to whether RFMOs have the requisite mandate or institutional dynamism to respond swiftly and effectively to projections of future climate-induced management problems. ${ }^{167}$ Ultimately, the most telling response is that suggested by the second Performance Review of the CCSBT, which recommended that the difficulties presented by shifting stocks of fish would be best addressed by 'developing an alternative approach to dispute settlement/conflict resolution to avoid the potential for future stalemates that could significantly compromise the conservation and management' of these stocks. ${ }^{168}$ This approach suggests that RFMOs are resignedly pragmatic as to their ability to address and mitigate distributional shifts, beyond providing supportive mechanisms to umpire the inevitable disputes between states over this issue, to which this chapter now turns.

\section{Future Challenges for Contested Mobile Resources}

Fisheries are frequently considered illustrative of the classic ecological conundrum of the 'tragedy of the commons', ${ }^{169}$ where a shared resource becomes depleted due to users promoting excessive self-interest over that of the common good. While not always an accurate depiction

\footnotetext{
161 FAO, Report of the Expert Meeting on Climate Change Implications for Mediterranean and Black Sea Fisheries (Rome, FAO, 2018) 15.

162 NAFO, NAFO Performance Review Panel Report 2018, 23.

163 Ibid., 24.

${ }^{164}$ NEAFC, Report of the Performance Review Panel 2014, 39-40.

165 Ibid. 40.

166 JA Nye et al., 'Changing Spatial Distribution of Fish Stocks in Relation to Climate and Population Size on the Northeast United States Continental Shelf’ (2009) 393 Marine Ecology Progress Series 111, 111.

${ }^{167}$ B Pentz and N Klenk, 'The "Responsiveness Gap" in RFMOs: The Critical Role of Decision-Making Policies in the Fisheries Management Response to Climate Change' (2017) 145 Ocean and Coastal Management 42, 49.

${ }_{168}$ CCSBT (n.159) Recommendation PR-2014-53.

${ }^{169}$ G Hardin, 'The Tragedy of the Commons' (1968) 162 Science 1243.
} 
of fishing practices, ${ }^{170}$ it is nevertheless also true that those in possession of access rights to fish have generally behaved uncharitably towards purported newcomers. Complaints of 'quotahoarding' are rife in a domestic context, ${ }^{171}$ with fishers unwilling even to relinquish habitually unused allocations without executive or judicial intervention. ${ }^{172}$ Similarly, behavioural science models predict that those states that are in the process of 'losing' fish through distributional shifts are more likely to exploit the stock unsustainably, ${ }^{173}$ driven by (well-founded) fears over a prospective future inability to freely access the resource. ${ }^{174}$

This bleak management prognosis stems from longstanding concerns over access to fisheries under current arrangements. International fisheries law has facilitated a cartel mentality towards fishing entitlements, in a manner that does not bode well for states seeking access to shifting stocks. As noted above, the stewardship of shared fish resources is subject to copious obligations of cooperation. In the context of straddling and highly migratory species, the UNFSA envisages that states fishing on the high seas and 'relevant coastal states' will discharge this obligation either by becoming members or participants in a regional fisheries management organisation or arrangement for those waters, or by agreeing to apply the resultant conservation and management measures adopted by that organisation or arrangement, ${ }^{175}$ with the ability to fish contingent upon adherence to these measures. ${ }^{176}$ Under Article 8(3), other states exhibiting a 'real interest' in the stock - a term that, alongside a 'relevant coastal state', was undefined in the UNFSA ${ }^{177}$ - should be able to become members or participants in this organisation or arrangements, without being impeded or discriminated against by existing constituents.

Nevertheless, the principle of pacta tertiis does not bind other states to such measures and essentially allows them to access the resource without participating in a regional management regime and accepting these constraints. ${ }^{178}$ In turn, existing constituents have imposed increasingly stringent requirements and disincentives for admission to RFMOs and arrangements in order to protect their share of the resource from new entrants, ${ }^{179}$ a trend that

\footnotetext{
${ }^{170}$ F Berkes, 'Fishermen and the Tragedy of the Commons' (1985) 12 Environmental Conservation 199; for a more modern view see A Serdy, The New Entrants Problem in International Fisheries Law (Cambridge, Cambridge University Press, 2016) 10-42.

${ }^{171}$ Dubik (n.63) 247.

172 Aptly illustrated in a UK context in $R$ (United Kingdom Association of Fish Producer Organisations) v. Secretary of State for the Environment, Food and Rural Affairs [2013] EWHC 1959 (Admin).

${ }^{173}$ FK Diekert and E Nieminen, 'International Agreements with a Shifting Stock' (2017) 7 Dynamic Games and Applications 185, 200-202.

174 Oremus (n.77) 277.

175 Article 8(3).

${ }^{176}$ Article 8(4)

${ }^{177}$ See further EJ Molenaar, "The Concept of "Real Interest" and Other Aspects of Co-operation through Regional Fisheries Management Mechanisms’ (2000) 15 International Journal of Marine and Coastal Law 475.

${ }^{178}$ On these difficulties see A Serdy, 'Pacta Tertiis and Regional Fisheries Management Mechanisms: The IUU Fishing Concept as an Illegitimate Short-Cut to a Legitimate Goal' (2017) 48 Ocean Development and International Law 345.

${ }^{179}$ For instance, NAFO and NEAFC have advised prospective new participants that, "presently and for the foreseeable future', their respective stocks have been 'fully allocated' with fishing opportunities for new members therefore likely to be restricted to new fisheries: see NAFO Resolution 1/99 of 17 September 1999 to Guide the Expectations of Future New Members with Regard to Fishing Opportunities in the NAFO Regulatory Area and the parallel Guidelines for the Expectation of Future New Contracting Parties with Regard to Fishing Opportunities in the NEAFC Regulatory Area, adopted at the Twenty-Second Annual Meeting of NEAFC in 2003. As noted above, some acknowledgement of the difficulties created by this stance in the context of distributional shifts has been acknowledged by NAFO (n.164).
} 
further disincentivises active cooperation by third states. ${ }^{180}$ In response, and with an understandable reluctance to feed the hand that bites them, members of RFMOs and arrangements become even less inclined to share a diminishing resource. ${ }^{181}$ Against this backdrop - and the lack of clear criteria by which states that are either losing or gaining fish may be considered 'relevant' or to have a 'real interest' in participating - has engendered unsustainable rates of fishing as states seek to avail themselves of a resource windfall or maintain access to a moving stock.

This has been most recently illustrated in the so-called 'mackerel war' of 2013, an episode that exemplifies the tragedy of the commons with dispiriting ease. Throughout much of the latter part of the Twentieth Century, the distribution of commercially valuable stocks of AtlantoScandian herring and North-East Atlantic mackerel had exhibited subtle shifts, raising potential conflicts between interested states. The herring stock initially collapsed due to rampant overfishing in the 1960s, before rallying and, in the process, changing its migratory route to remain largely confined to Norwegian waters. ${ }^{182}$ A similar pattern appears to have characterised the mackerel stock, which followed a familiar trend of boom-and bust, before rebooming along a different geographical pathway. ${ }^{183}$

A series of substantial distributional shifts, largely attribute to climate change, nevertheless began to create management and political difficulties in relation to both stocks. Until 2009, mackerel was primarily apportioned trilaterally between the EU, Norway and the Faroe Islands and bilaterally between the EU and Norway as 'relevant' coastal states, albeit excluding Iceland, which had begun to fish the increasing volumes of fish now displaced into its EEZ. ${ }^{184}$ These participants subsequently failed to establish mutually acceptable allocations until a fiveyear agreement was brokered in $2014,{ }^{185}$ granting additional entitlements to the Faroe Islands, albeit omitting other interested - and arguably 'relevant' ${ }^{186}$ - coastal states, much to the chagrin of Iceland.

In the context of herring - which ultimately constituted the main prize at stake in the perhaps inaptly named 'mackerel war' - matters came to a head in 2013, following the steady displacement of an increasing proportion of the stock into the EEZ of the Faroe Islands. Quota for herring has been historically apportioned between the EU, Faroe Islands, Iceland, Norway and Russia pursuant to the Atlanto-Scandian Management Arrangements (ASMA). As with many arrangements in which the EU is an assertive participant, ${ }^{187}$ management decisions are taken in line with its favoured principle of relative stability, ${ }^{188}$ which is based primarily on

180 Serdy (n.170) 43-140.

${ }^{181}$ On the spiralling problems of this mindset see A Serdy, 'Postmodern International Fisheries Law, Or We Are All Coastal States Now' (2011) 60 International and Comparative Law Quarterly 387.

${ }^{182}$ E Sissener and T Bjørndal, 'Climate Change and the Migratory Pattern for Norwegian Spring-spawning Herring-Implications for Management' (2005) 29 Marine Policy 299, 300-305.

183 T Jansen, 'Pseudocollapse and Rebuilding of North Sea Mackerel (Scomber scombrus)' (2014) 71 ICES Journal of Marine Science 299.

${ }^{184}$ For an excellent survey of these developments see P Ørebech, "The "Lost Mackerel" of the North East Atlantic - The Flawed System of Trilateral and Bilateral Decision-making' (2013) 28 International Journal of Marine and Coastal Law 343.

185 Reproduced at https://ec.europa.eu/fisheries/sites/fisheries/files/docs/body/2014-2018-agreed-record-eufaroe-islands-norway-mackerel_en.pdf.

186 Ørebech (n.184) 362.

187 See RR Churchill, 'The EU as an International Fisheries Actor - Shark or Minnow?' (1999) 4 European Foreign Affairs Review 463.

${ }^{188}$ R Churchill and D Owen, The EC Common Fisheries Policy (Oxford, Oxford University Press, 2010) 149154. 
historical catches, rather than zonal attachment, which proceeds in line with the current location of the fish. Under the ASMA, the Faroe Islands received an agreed share of 5.16\% of the stock, an allocation that was increasingly meagre in proportion to the distributional pattern of the fish. ${ }^{189}$ These circumstances prompted the Faroe Islands to agitate for a higher entitlement, leveraged against the physical presence of the stock within its national waters. Nevertheless, with scientific advice in 2012 recommending a $26 \%$ reduction in TAC, and with the other participants loathe to correspondingly reduce their respective entitlements, the Faroe Islands withdrew from the Arrangements and unilaterally set a catch limit of $17 \%$ of the TAC within its EEZ, representing a threefold increase in catches. ${ }^{190}$ The EU accordingly designated the Faroe Islands as a 'country allowing non-sustainable fishing' and imposed a series of trade restrictions and access limitations to EU ports. ${ }^{191}$ In response, Denmark initiated arbitration proceedings under Annex VII of the LOSC, ${ }^{192}$ as well as a request for consultations before the World Trade Organization (WTO). ${ }^{193}$

These proceedings were ultimately discontinued by Denmark once revised arrangements with other coastal states in favour of the Faroe Islands were forthcoming. ${ }^{194}$ Nevertheless, while judicial intervention was averted, significant concerns may be expressed over the manner in which this dispute was ultimately resolved. The settlement resulted only in a recasting of entitlements that were numerically acceptable to the existing protagonists, without measured thought as to the long-term future of the fishery. Moreover, it served to marginalise other interests in the stock, who are legitimately entitled to pursue these fish within their national waters, ${ }^{195}$ for which the outcome will be an inevitably unsustainable volume of combined catches. A more measured reappraisal of entitlements, based predominantly on zonal attachment and on a real-time understanding of a stock distribution in flux is unlikely to materialise, given the long-standing vested interest of the current participants, notwithstanding its conceptual attractions. ${ }^{196}$ Instead, the 'mackerel war' suggests that the most effective political solution to stock shifts will be a sustained period of brinkmanship followed by a concerted volume of overfishing.

More constructive approaches have nevertheless emerged, albeit on a more localised level, that have increasingly moved away from relatively stability - or have adopted a more flexible understanding of this concept - as an underlying model for fisheries allocations. Indeed, many longstanding fisheries arrangements, and the historical catches on which such understandings are based, were developed when the stock in question inhabited a markedly cooler ocean and were dispersed in more southerly locations. ${ }^{197}$ Nationally, fisheries managers have recognised that meaningful consultations with those most closely affected, while also adopting flexible

${ }^{189}$ Regulation (EU) No 793/2013 of 20 August 2013 establishing measures in respect of the Faeroe Islands to ensure the conservation of the Atlanto-Scandian herring stock [2013] Official Journal L223/1.

${ }^{190}$ Ibid., recitals 7-9.

${ }^{191}$ Ibid., Article 5.

192 The Atlanto-Scandian Herring Arbitration (The Kingdom of Denmark in respect of the Faroe Islands v. The European Union); PCA Case No 2013-30.

193 European Union - Measures on Atlanto-Scandian Herring; WT/DS469 https://www.wto.org/english/tratop_e/dispu_e/cases_e/ds469_e.htm.

${ }^{194}$ The Atlanto-Scandian Herring Arbitration (The Kingdom of Denmark in respect of the Faroe Islands v. The European Union), Termination Order of 23 September 2014. The WTO dispute was terminated on 21 August 2014.

195 Ørebech (n.184) 365-369.

196 Ibid. 371.

${ }^{197}$ P Gullestad, S Sundby and OS Kjesbu, 'Management of Transboundary and Straddling Fish Stocks in the Northeast Atlantic in View of Climate-induced Shifts in Spatial Distribution' (2020) 21 Fish and Fisheries (in press). 
approaches to landings, may mitigate the sensitivities inherent in transitioning away from an emphasis upon relative stability in addressing stock shifts. ${ }^{198}$

This is more challenging to implement beyond the domestic sphere - but is by no means impossible to achieve. On a bilateral level, states have demonstrated that they are prepared to phase out a reliance upon historical catches and to integrate a more nuanced series of allocative practices based on the physical location of the fish. This has been exemplified by far-sighted arrangements between the US and Canada over multiple stocks of groundfish (including commercially significant stocks of cod and haddock) in the Georges Bank where, in a sevenyear transitional period between 2003 and 2010, the weighting accorded to historical landings steadily diminished from $40 \%$ to $10 \% .{ }^{199}$ However, this approach is not without trade-offs. While providing a transparent mechanism to remodel allocations on a shifting stock, this has inevitably led to fisheries management on a single-species basis, rather than the ecosystembased management to which fisheries regulation broadly aspires to attain. ${ }^{200}$

Elsewhere, other collegiate approaches to stock fluctuations have emerged. One example that has been promoted as a means of prospectively addressing climate change impacts on fisheries is the Vessel Day Scheme (VDS), ${ }^{201}$ adopted under the Palau Arrangement, an Implementing Agreement to the Nauru Agreement Concerning Cooperation in the Management of Fisheries of Common Interest 1982, ${ }^{202}$ which allows for the transfer of fishing days between the participants in order to mitigate the stock fluctuations. Nevertheless, this programme has not been extended further under the wider auspices of the $\mathrm{WCPFC}^{203}$ and doubt has been cast upon its broader feasibility without extensive side payments to discourage the 'race-to-fish' habitually experienced with stock shifts. ${ }^{204}$

\section{Conclusions}

Climate change has been evocatively portrayed as a 'legally disruptive' phenomenon that will continue to stress-test laws and institutions in a series of unprecedented and unforeseen ways. $^{205}$ This is particularly apparent in the context of marine living resources, for which regulatory regimes have traditionally favoured largely static management, underpinned by a working hypothesis that stocks are unlikely to exhibit vast shifts in historical coverage and habitat preferences. Rapidly altering oceanic conditions, increasingly driven by climate change and associated impacts, are nevertheless exposing the flaws inherent in these continued assumptions. Thus far, the scholarship on the impacts of climate change upon the central tenets of the law of the sea has predominantly considered coastal erosion and the potentially

\footnotetext{
${ }^{198}$ Dubik (n.63) 247-249; T Young et al., 'Adaptation Strategies of Coastal Fishing Communities as Species Shift Poleward' (2020) 76 ICES Journal of Marine Science 93, 99-101.

199 EJ Pudden and DL VanderZwaag, 'Canada-United States Bilateral Fisheries Management in the Gulf of Maine: Struggling Towards Sustainability under the Radar Screen' in DA Russell and DL VanderZwaag, Recasting Transboundary Fishery Management Arrangements in the Light of Sustainability Principles: Canadian and International Perspectives (Leiden, Martinus Nijhoff, 2010) 177, 183-185.

${ }^{200}$ Ibid. 198-199.

${ }^{201}$ T Aqorau, J Bell and JN Kittinger, 'Good Governance for Migratory Species' (2018) 361 Science 1208.

${ }^{202}$ See https://www.ffa.int/nauru_agreement ('Nauru Agreement').

203 Serdy (n.170) 334-335.

204 Oremus (n.77) 279.

${ }^{205}$ E Fisher, E Scotford and E Barritt, 'The Legally Disruptive Nature of Climate Change' (2017) 80 Modern Law Review 173.
} 
ambulatory nature of national baselines. ${ }^{206}$ It is increasingly evident, however, that the most significant and contested implications of climate change on marine entitlements will involve shifting marine living resources rather than a subtle reconfiguration of jurisdictional waters.

Climate change exhibits ample scope to disrupt longstanding achievements and certainties in international law, particularly in the context of fisheries. In extreme cases, a stock shift could prove so dramatic as to eventually render a single-species RFMO functionally redundant, ${ }^{207}$ or prompt states to seek to renegotiate jurisdictional boundaries associated with fisheries entitlements. $^{208}$ The shifting distribution of marine living resources may even gain some traction in future boundary delimitations as a 'catastrophic repercussion' requiring corrective equity, ${ }^{209}$ although it remains to be seen whether this would be sufficient to overcome the traditional ambivalence accorded to fisheries in such processes, ${ }^{210}$ even where fish stocks are a central element of national claims. ${ }^{211}$ Meanwhile, changing ocean conditions remain a particularly pervasive environmental stressor that will exacerbate existing challenges facing fisheries managers at all tiers of governance, ${ }^{212}$ and the socio-economic implications of shifting stocks have the propensity to generate considerable discord between interested states and to aggravate pre-existing geopolitical fractures. ${ }^{213}$

Thus far, international law has proved slow to respond to these challenges, although examples of far-sighted practices are nevertheless apparent. Most recently, a strikingly novel approach has been adopted to frame future fisheries management in the Arctic, pre-empting a prospective influx of new fish species into these waters and elaborating a highly precautionary new regime to address such stocks, if and when commercial and biological conditions are conducive to concerted fishing activities. In Antarctica, a series of mechanisms have been developed to establish precautionary limits on the fishing of new stocks, which have been exported to other RFMOs, and in new marine areas created by climate change. RFMOs have adopted a series of collaborative practices that provide a basis for cooperation in the event of displaced stocks, and in some instances have adopted pragmatic solutions to managerial overlaps. Individual states have also brokered arrangements to reallocate fishing entitlements for shifting species in a manner than is more reflective of prevailing distributions, yet sensitive to those with a historical interest in the stock.

\footnotetext{
206 Although this reveals that the loss of jurisdictional entitlements through climate change are necessarily as automatic as may be popularly presumed: K Purcell, Geographical Change and the Law of the Sea (Oxford, Oxford University Press, 2019) 260-286.

${ }^{207}$ Rayfuse (n.68) 268.

${ }^{208}$ S Árnadóttir, 'Ecological Changes Justifying Termination or Revision of EEZ and EFZ Boundaries' (2017) 84 Marine Policy 287.

${ }^{209}$ Case Concerning Delimitation of the Maritime Boundary in the Gulf of Maine Area (Canada v. United States of America); Judgment of 12 October 1984 [1984] ICJ Rep 340, para 237.

${ }^{210}$ See further RR Churchill, 'Fisheries Issues in Maritime Boundary Delimitation' (1993) 17 Marine Policy 44, 53 and RR Churchill, 'The Greenland-Jan Mayen Case and its Significance for the International Law of Maritime Boundary Delimitation' (1994) 9 International Journal of Marine and Coastal Law 1, 21-22

${ }^{211}$ Gulf of Maine case (n.209); Maritime Delimitation in the Area between Greenland and Jan Mayen (Denmark v. Norway); Judgment of 14 June 1993 [1993] ICJ Rep 38. On the general treatment of fisheries see M Evans, 'Relevant Circumstances' in AG Oude Elferink, T Henriksen and SV Busch, Maritime Boundary Delimitation: The Case Law. Is It Consistent and Predictable? (Cambridge, Cambridge University Press, 2018) 222, 253-256 and Y Tanaka, Predictability and Flexibility in the Law of Maritime Delimitation (Oxford, Hart, 2019) $370-393$. ${ }^{212}$ Free (n.62) 979.

${ }^{213}$ J García Molinos et al., 'Climate Velocity and the Future Global Redistribution of Marine Biodiversity’ (2015) 6 Nature Climate Change 83, 87 (observing that distributional shifts are occurring in areas encompassing 'some of the world's most vexing maritime territorial disputes', notably the East and South China Seas).
} 
Nevertheless, these burgeoning achievements remain the exception, rather than the rule. The pioneering Arctic arrangements are fundamentally untested, with indications that commercial opportunity may ultimately trump precautionary aspiration. Similarly, RFMOs have generally lacked the mandate, resources, political consensus and arguably the inclination to address the broader challenges associated with climate change, including distributional shifts. Moreover, the 'mackerel war' vividly illustrates the problems inherent in confronting the management challenges posed by shifting stocks: the current position largely disincentives states to relinquish historical entitlements over fish that are now eminently exploitable by other states, which in turn may find themselves excluded from participation in the fishery and must therefore resort to unilateralism. The likely solution to this conundrum appears to be a compensatory mechanism to encourage a rebalancing of allocative practices based more closely upon zonal attachment, although this has largely eluded the international community to date. Ultimately, shifting stocks will need to be addressed in an environmentally-sensitive manner, based on meaningful cooperation between states and supported by effective institutional arrangements, with an emphasis upon effective dispute resolution and underpinned by a sense of realism as to the barriers presented by state interests, as aptly and amply demonstrated in the rich and enduring legacy of fisheries scholarship of Robin Churchill. 